\title{
Effects of shallow-layer reverberation on measurement of teleseismic P-wave travel times for ocean bottom seismograph data
}

\author{
Masayuki Obayashi ${ }^{*} \mathbb{D}$, Yasushi Ishihara ${ }^{2}$ and Daisuke Suetsugu ${ }^{1}$
}

\begin{abstract}
We conducted synthetic experiments to evaluate the effects of shallow-layer reverberation in oceanic regions on P-wave travel times measured by waveform cross-correlation. Time shift due to waveform distortion by the reverberation was estimated as a function of period. Reverberations in the crystalline crust advance the P-waves by a frequency-independent time shift of about $0.3 \mathrm{~s}$ in oceans. Sediment does not affect the time shifts in the mid-ocean regions, but effects as large as $-0.8 \mathrm{~s}$ or more occur where sediment thickness is greater than $600 \mathrm{~m}$ for periods longer than $15 \mathrm{~s}$. The water layer causes time delays $(+0.3 \mathrm{~s})$ in the relatively shallow $(<3500 \mathrm{~m})$ water region for periods longer than $20 \mathrm{~s}$. The time shift may influence mantle images obtained if the reverberation effects are not accounted for in seismic tomography. We propose a simple method to correct relative P-wave travel times at two sites for shallow-layer reverberation by the cross-convolution of the crustal responses at the two sites.
\end{abstract}

Keywords: Crustal reverberation, Waveform distortion, Travel time correction, Ocean bottom seismometer, Mantle tomography

\section{Background}

A seismic array observation with broadband ocean bottom seismograph (BBOBS) has become a common tool for investigating the structure of the Earth's interior [see review by Suetsugu and Shiobara (2014)]. Compared with land-based seismic records, BBOBS records are contaminated by (1) tidal noise due to deep currents and (2) signal-generated noise by reverberation in shallow layers (e.g., Blackman et al. 1995). (In the present study, water/ice, sediment, and the crystalline crust are considered as "shallow layers" and the "crust layer" refers to the crystalline crust.) The former has a peak in the period range of 3-5 s, which overlaps with periods of teleseismic body waves. It is common to apply a lowpass or bandpass filter to BBOBS records to avoid this noise peak. Meanwhile, the shallow-layer reverberation is excited by seismic waves, which is composed of reflection/conversion

\footnotetext{
*Correspondence: obayashi@jamstec.go.jp

${ }^{1}$ Department of Deep Earth Structure and Dynamics Research, Japan Agency for Marine-Earth Science and Technology, 2-15 Natsushima-cho, Yokosuka 237-0061, Japan

Full list of author information is available at the end of the article
}

in the shallow layers. The largest reverberation occurs in the water and sediment layers and is periodic with a time interval that approximates two-way travel time of sound in the water; thus, the time interval is about 5 and $8 \mathrm{~s}$ for 4 and 6-km seafloors, respectively, which could interfere with the teleseismic body waves. Furthermore, filtering out tidal noise complicates the interference of teleseismic body waves with the shallow-layer reverberation, which could result in a waveform distortion and a bias in travel time measurements by waveform cross-correlation of teleseismic body waves (Blackman et al. 1995). This bias is frequency dependent, which may cause a bias in mantle images obtained by finite-frequency tomography using BBOBS data (Obayashi et al. 2013, 2016). Obayashi et al. (2004) addressed the effects of shallow-layer reverberation on PP-phases in PP-P differential time measurements. Yang and Shen (2006) and Kolstrup and Maupin (2015) addressed the effects of crustal reverberation on P-wave travel times at continental stations and proposed a simple method to correct travel times for the effect.

In the present study, we focused on the shallow-layer reverberation effects on teleseismic P-waves recorded 
on the seafloor with BBOBSs, where the reverberation effects are greater than those by broadband records on land. In particular, we estimated the effects on P-wave travel times measured with waveform cross-correlation and their frequency dependence by calculating synthetic seismograms using realistic shallow-layer models. In addition, we estimated the shallow-layer effect on the measurement of relative travel times of teleseismic $\mathrm{P}$-waves recorded by an oceanic seismic array, which is a common method to extract the travel time information of teleseismic P-waves from BBOBS data (e.g., Wolfe et al. 2009, 2011; Obayashi et al. 2013, 2016). We were then able to propose a simple method to correct the relative travel times for shallow-layer reverberation.

\section{Time shift by waveform distortion due to shallow-layer reverberation}

We compared a P-wave waveform incident to the Moho with P-wave waveforms observed on seafloors to estimate the apparent time shifts caused by shallow-layer reverberations, including those in sediment and water layers. We assumed that the incident wave pulse was the first derivative of an impulsive function attenuated along the raypath from $0-\mathrm{km}$-depth focus to the station at an epicentral distance of $80^{\circ}$. We applied the $t^{*}$ operator to account for the attenuation using a $t^{*}$ value of 1.0, which is typical for teleseismic P-waves. To synthesize waveforms on the seafloor (hereafter referred to as OBS waveform), we calculated the response for a shallowlayer structure using the Haskell matrix method (Haskell 1962) and convolved it with the incident wave. Figure 1 shows the synthetic OBS waveforms for the crustal structure given in Table 1 in comparison with the incident waveform. Narrow bandpass filters with central periods of $2.7,5.3,7.5,10.6$, and $21.2 \mathrm{~s}$ were applied. The OBS waveform is shifted in time by the ray theoretical travel time through the shallow layer so that the onset of its first $\mathrm{P}$-wave phase is the same as the incident phase. The OBS waveform at the period of $2.7 \mathrm{~s}$ shows clear reverberations caused mainly by the seawater and sediment layers after the first phase incident from below. Upon application of the longer-period bandpass filters, the first phase waveform was distorted by interference from the following reverberations. This distortion causes a discrepancy in the time shift obtained by cross-correlation between the incident waveform and the OBS waveform among the different periods of the bandpass filters. Here, we define the time shift as the time difference corrected for the ray theoretical travel time in the shallow layer. We estimated the time shift for shallow layers with various thicknesses of seawater and sediment layers from 0 to $10,000 \mathrm{~m}$. The shallow-layer properties except for the thicknesses of the seawater and sediment layers were fixed to the values

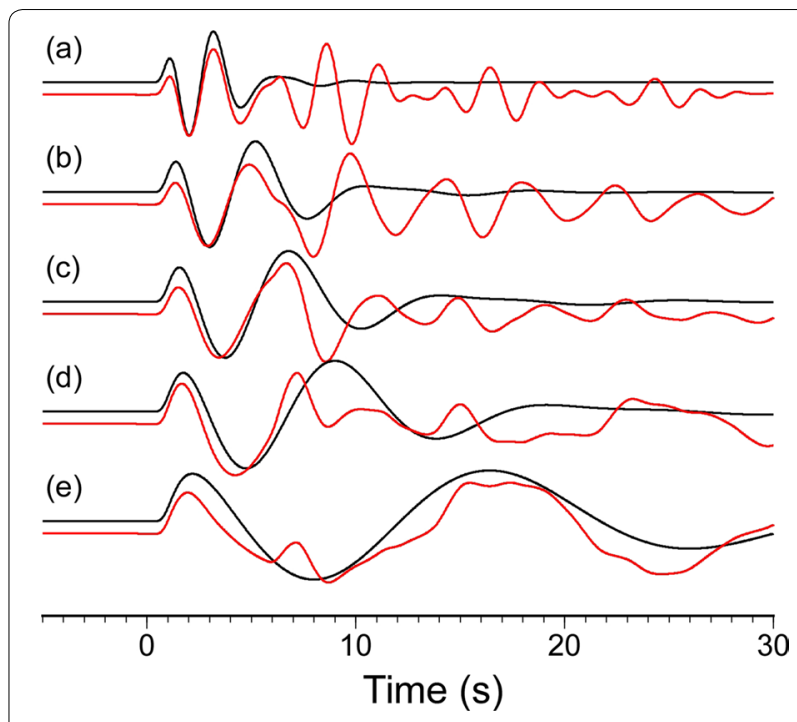

Fig. 1 Black Waveforms incident to the Moho. Red waveforms synthesized by convolving the crustal response for a crustal structure as shown in Table 1 with the incident waveform. Bandpass filter is applied at a central period of (a) $2.7 \mathrm{~s}$, (b) $5.3 \mathrm{~s}$, (c) $7.5 \mathrm{~s}$, (d) $10.6 \mathrm{~s}$, and (e) $21.2 \mathrm{~s}$

shown in Table 1. We selected the time windows for the cross-correlation on the incident waveforms according to the wave periods to ensure that all windows contained at least one cycle of the waves. Figure 2 shows the relationships of the time shift with seawater depth and sediment thickness. The time shift can be both positive and negative according to the combinations of seawater depth and sediment thickness. The time shift is close to zero for the period of $2.7 \mathrm{~s}$ because the reverberations are sufficiently temporally separated so as not to interfere with the first phase. The absolute values of the time shift increase with the wave period, because a longerperiod wave is more susceptible to contamination from the shallow-layer reverberation with a long duration, up to $1.86 \mathrm{~s}$ for the period of $21.2 \mathrm{~s}$. The time shift exhibits significant dependence on water depth. For a given sediment thickness, the shift could be either positive or negative, depending on the water depth. The water layer has a characteristic depth that causes large positive time shifts: about 1000, 1500, and $3000 \mathrm{~m}$ for a period of 7.5 ,

Table 1 Seismic velocity, density and thickness of seawater, sediment and crust layers used for Figs. 1 and 2

\begin{tabular}{lllll}
\hline & Seawater & Sediment & Upper crust & Lower crust \\
\hline$V p(\mathrm{~km} / \mathrm{s})$ & 1.500 & 1.600 & 5.525 & 6.900 \\
$V s(\mathrm{~km} / \mathrm{s})$ & 0.000 & 0.879 & 3.250 & 3.875 \\
$\rho\left(\mathrm{g} / \mathrm{cm}^{3}\right)$ & 1.029 & 2.000 & 2.720 & 2.920 \\
Thickness $(\mathrm{km})$ & 4.000 & 1.000 & 1.500 & 5.000 \\
\hline
\end{tabular}




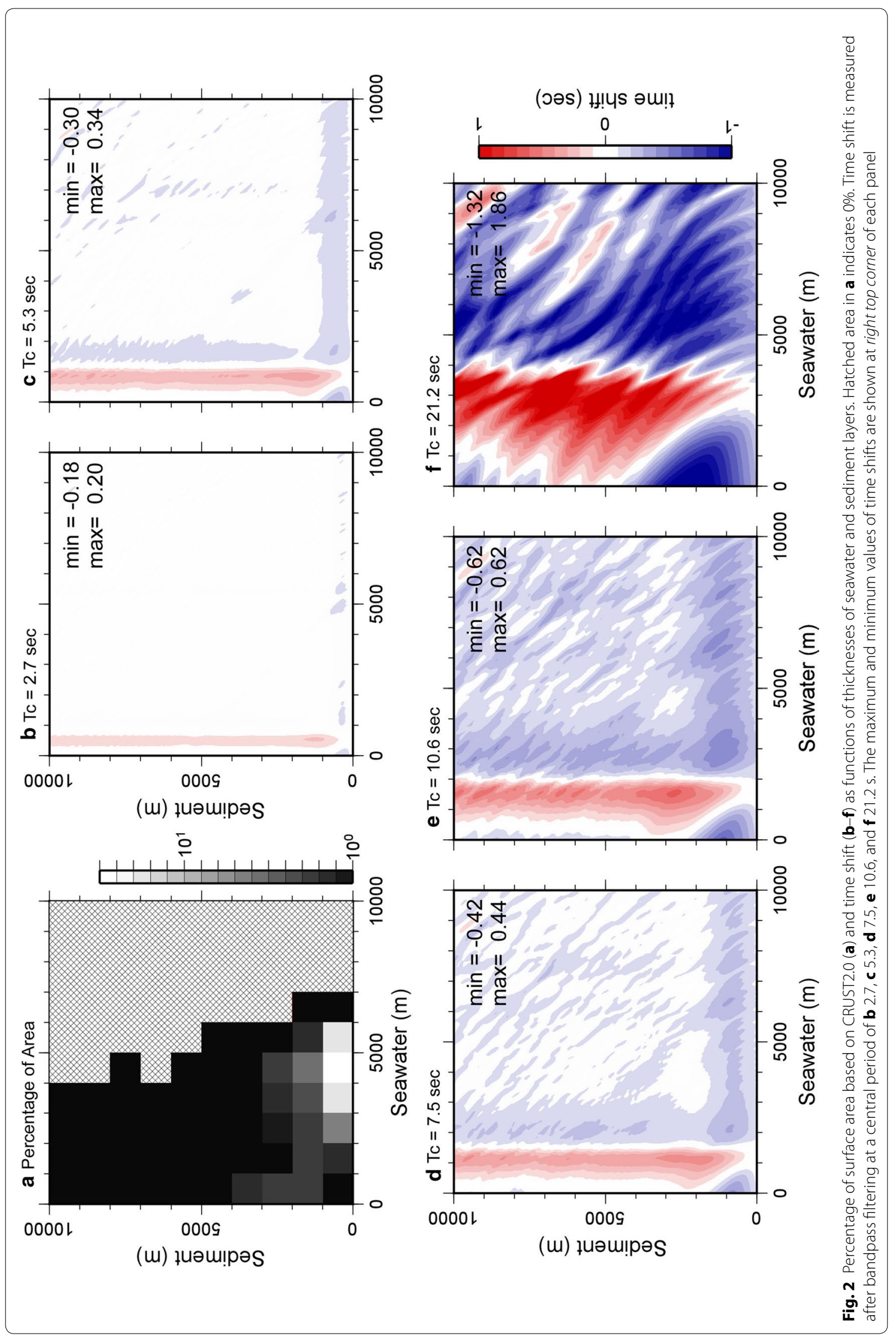


10.6, and $21.2 \mathrm{~s}$, respectively. For a given water depth, the effect of the sediment thickness is nearly constant for sediments greater than $1000 \mathrm{~m}$. Care should be taken when measuring relative P-wave travel times, especially at sites with thick sediment layers $(>1000 \mathrm{~m})$ such as back arc basins and the seas adjacent to continents.

Because the range of thickness of seawater and sediment layers on Earth is limited (Fig. 2a), we estimated the time shifts using the $2^{\circ} \times 2^{\circ}$ crustal model: CRUST2.0 (Bassin et al. 2000). Additional file 1: Fig. A shows the CRUST2.0 distributions of bathymetry, sediment thickness, and crust layer thickness. Figure 3 shows the global distribution of the frequency-dependent time shift. There is only a small uniform time shift (within $\pm 0.2 \mathrm{~s}$ ) at periods of $2.7-7.5 \mathrm{~s}$. The effect of the shallow-layer reverberation increases from -0.2 to $-0.5 \mathrm{~s}$ with increasing periods from 10.6 to $21.2 \mathrm{~s}$. In particular, in regions with thick sediment layers, such as off the coasts of India and off of southeast South America, the time shifts are as large as $-0.8 \mathrm{~s}$. Alternatively, the time shifts are small in the shallow seafloor along spreading ridges and less significant in the middle of the ocean at a period of $30 \mathrm{~s}$ (within $\pm 0.2 \mathrm{~s}$ ). Figure 4 presents examples of the wave field without and with the reverberations in CRUST2.0 at sites with different water depths and sediment thicknesses, and Table 2 lists the time shifts at the different periods for these sites.

Figure 5 summarizes the time shifts in terms of seawater, sediment and crust layer thicknesses. Several trends are apparent, although crust layer thickness, sediment thickness, and seawater depth are not independent. For instance, regions with thick crust usually involve shallow seawater and thick sediments. The shift time has a maximum at a sea depth and the sea depth of the maximum increases as the period of the bandpass filter increases. This is considered attributable to the time interval of the seawater reverberations. The time shift is poorly correlated with the thicknesses of the sediment and crust layers, while their mean values become negatively larger at a period of $30.0 \mathrm{~s}$ in the ranges of $3-16 \mathrm{~km}$ and $10-30 \mathrm{~km}$ for sediment and crust thicknesses, respectively.

Next, we examine the effect of the three layers separately on the time shift: First, we calculated time shifts due solely to the crust layer by removing the water and sediment layers from CRUST2.0 (Fig. 6). The time shifts are slightly negative at periods shorter than 7.5 and $-0.3 \mathrm{~s}$ at periods longer than $10.6 \mathrm{~s}$. The time shift is spatially uniform mainly because the crust structure is almost uniform in CRUST2.0. The crustal time shifts in the large igneous provinces or back-arc basins are also similar to those near the mid-ocean region. Next, we examined the effect of the sediment layer by removing the crust and water layers. The time shifts due to the sediment layer model have negative values (Fig. 7). The effect is negligible in the mid-oceanic regions, where sediment is thinner than $600 \mathrm{~m}$. Meanwhile, it is much more significant for thicker sediments, becoming larger with longer periods. Regions with thick sediment layers include back-arc regions, seas adjacent to continents, and the Arctic Ocean. The time shifts reach $-1.0 \mathrm{~s}$ at a period of $30 \mathrm{~s}$. Finally, we examined the effect of the water and ice layers (Fig. 8). The time shift due to seawater is almost zero at periods shorter than $15.0 \mathrm{~s}$. We observed a correlation between the time shift and water depth at longer periods. Positive time shifts of $0.2-0.4 \mathrm{~s}$ were observed in the seafloor along spreading ridges at a period of $21.2 \mathrm{~s}$ and in seafloor shallower than $3000 \mathrm{~m}$ at a period of $30.0 \mathrm{~s}$. The time shift calculated from CRUST2.0 looks approximately like a superposition of the time shifts estimated separately from the crust, sediment, and water layer models. The interactions among reverberations in each layer does not significantly affect the P-wave travel times. The contributions of crust, sediment, and water layers to the time shift can be summarized as follows. Oceanic crust results in negative time shift $(-0.3 \mathrm{~s})$ at periods longer than $10 \mathrm{~s}$. Sediment does not affect the time shifts in mid-ocean regions, but affects them significantly where sediment thickness is greater than $600 \mathrm{~m}$ at periods longer than $10 \mathrm{~s}$. Water layer results in positive time shifts $(+0.3 \mathrm{~s})$ in relatively shallow $(<3500 \mathrm{~m})$ water regions at periods longer $20 \mathrm{~s}$.

\section{Effect on relative travel times and its correction}

Next, we dealt with the relative P-wave travel times among stations in a seismic array, which have often been measured and used for recent seismic tomography (Wolfe et al. 2009, 2011; Obayashi et al. 2013, 2016). We examined the effects of shallow-layer reverberation on the relative travel times and methods for correcting the effects of reverberation in the study of P-wave tomography for the mantle structure. As an extreme case, we assumed that one station was located on the seafloor and the other was on land. The shallow-layer structures at the two sites are shown in Table 3. The seafloor was set to a depth of $4000 \mathrm{~m}$ deep, and the sediment thickness was $500 \mathrm{~m}$ (called the "seafloor model"). We used the AK135 model (Kennett et al. 1995) for the land site. The mantle structure of the seafloor model was taken from the AK135 model. We calculated synthetic seismograms using the two models with the Direct Solution Method (Takeuchi et al. 1996) for a focal depth of $600 \mathrm{~km}$ and an epicentral distance of $80^{\circ}$. The top panel of Fig. 9 shows the synthetic seismograms from the two models. The synthetics for the seafloor model are shown in red, after shifting in time by the travel time difference between two shallow-layer models as predicted via ray theory 


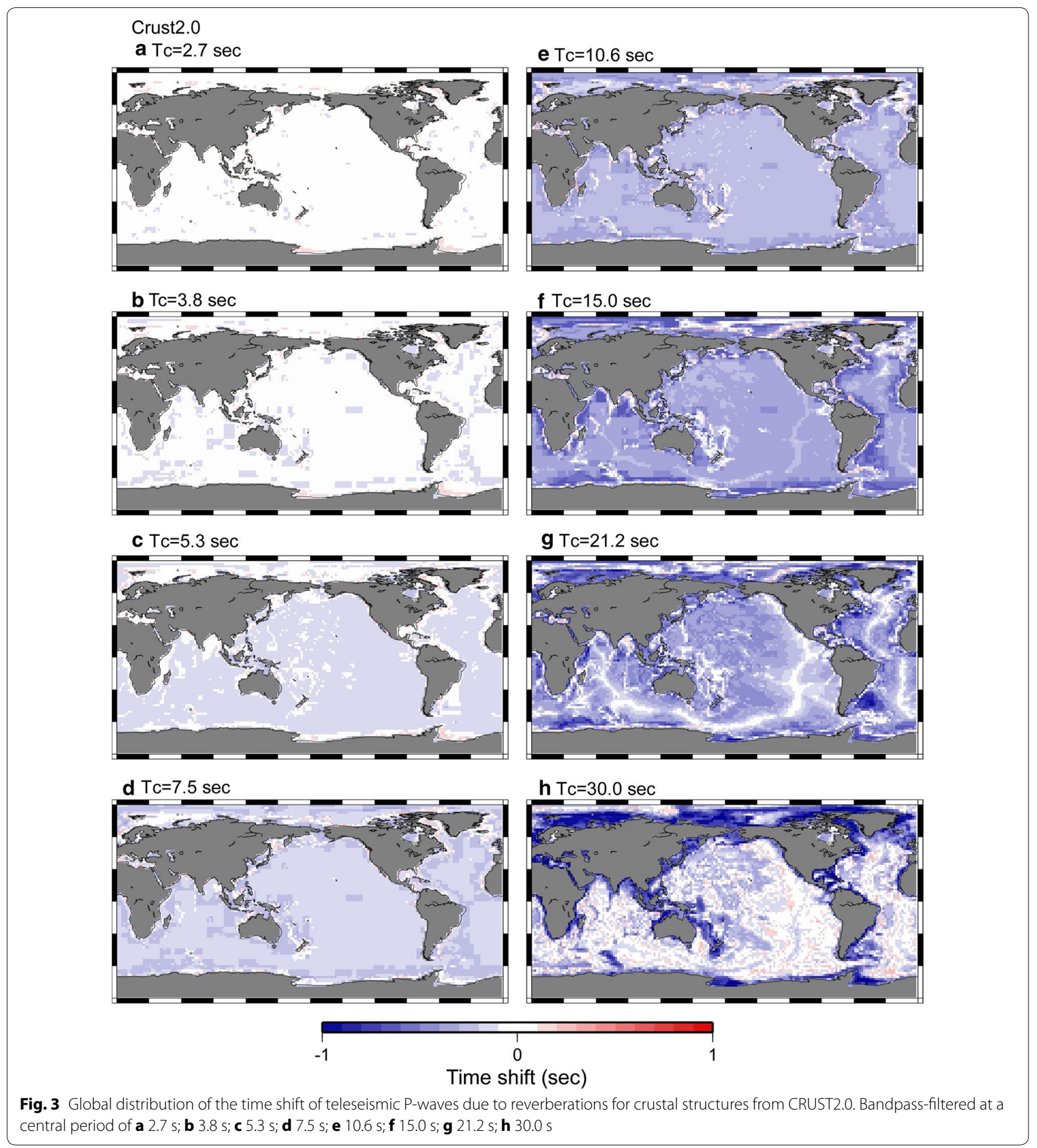

(the P-wave for the seafloor model arrives faster than the AK135 model because of the deeper site location and thinner crustal layer). The synthetics are indicated by the broken blue lines at times of maximum correlation with the synthetics for the AK135 model. Therefore, the difference in time between the red and blue waveforms can be considered the time shift due to the different shallowlayer structures at the two sites. Shallow-layer reverberations, mainly from water and sediment layers, are clearly observed for the seafloor model at a period of $2.7 \mathrm{~s}$ and their interferences with the main P-wave are apparent at longer periods. Time shifts are clearly observed for the 


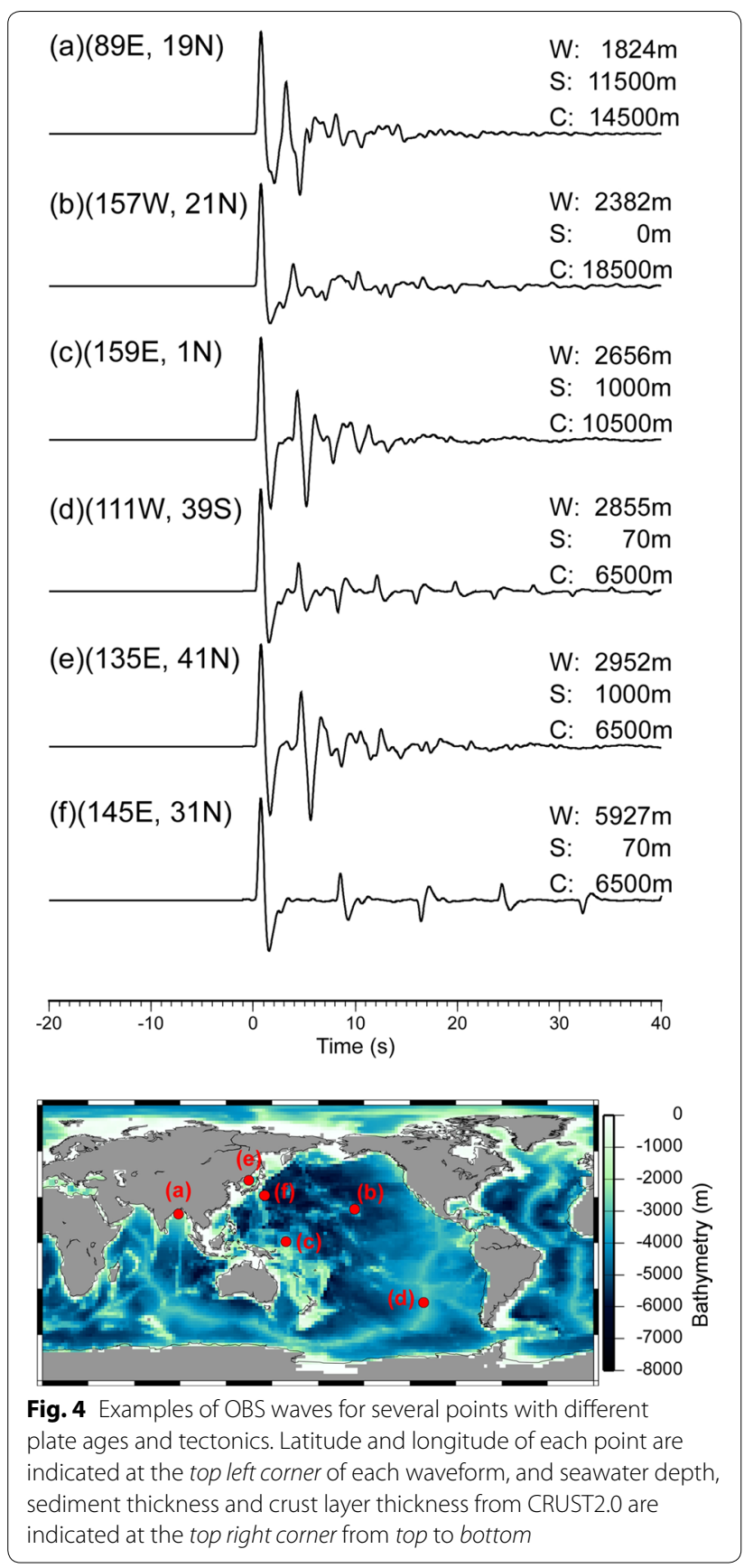

waveforms at the periods of 7.5 and $10.6 \mathrm{~s}$. We measured the differential travel time between the two stations as a function of the period by cross-correlating synthetics from the two models using eight different bandpass filters at center periods of $2.7,3.8,5.3,7.5,10.6,15.0,21.2$, and $30.0 \mathrm{~s}$. Figure 10 shows the measured differential travel times after correction for ray theoretical travel time difference (i.e., time shift). Smaller time shifts signify a smaller effect from shallow-layer reverberation on travel time, which is desirable for mantle tomography. The time shift becomes significant, up to about $0.3 \mathrm{~s}$, at the periods of 7.5 and $10.6 \mathrm{~s}$, which may influence mantle images if the crustal effects are not accounted for in seismic tomography.

We propose a simple method to correct for the effects of the shallow-layer reverberation in measuring the relative travel time between the two stations by cross-correlation. Waveforms at the $i$ th and $j$ th stations $u_{i}(t)$ and $u_{j}(t)$ are expressed by convolution as:

$$
\begin{aligned}
& u_{i}(t)=f_{i}(t) * r_{i}(t) \\
& u_{j}(t)=f_{j}(t) * r_{j}(t)
\end{aligned}
$$

where $f_{i}$ and $f_{j}$ are the incident waveforms at the bottom of the crust at the $i$ th and $j$ th stations, which are not contaminated by shallow-layer structure beneath the stations, $r_{i}$ and $r_{j}$ are the responses for the shallow-layer structures at the two stations. We can correct the crustal effects by performing a cross-convolution of the waveforms $u_{i}$ and $u_{j}$ with $r_{j}$ and $r_{i}$, respectively, as follows:

$$
\begin{aligned}
& u_{i j}(t)=u_{i}(t) * r_{j}(t)=f_{i}(t) * r_{i}(t) * r_{j}(t) \\
& u_{j i}(t)=u_{j}(t) * r_{i}(t)=f_{j}(t) * r_{j}(t) * r_{i}(t)
\end{aligned}
$$

Since $u_{i j}$ and $u_{j i}$ are equalized for the effect of the shallow-layer reverberation, the cross-correlation of $f_{i}$ and $f_{j}$, which represents mantle effects, is same as that of $u_{i j}$ and $u_{j i}$. We can obtain a time shift that is uncontaminated by the shallow-layer reverberation from the cross-correlation of $u_{i j}$ and $u_{j i}$. Figure 10 shows that the corrected time shifts are almost zero. To remove the shallow-layer reverberation effect, it is theoretically correct to perform deconvolution of the crustal response $r(t)$ from the original waveform $u(t)$ to obtain $f(t)$. The cross-convolution (3) and (4) is, however, more feasible, since it is numerically stable as compared with the deconvolution.

\section{Discussion and conclusion}

We showed that the oceanic shallow-layer reverberation causes to advance/delay P-wave travel times measured by waveform cross-correlation. This time shift depends on frequency and thus induces dispersion. The time shifts estimated from CRUST2.0 are mostly negative, while they can be positive or negative under the conditions of seawater and sediment thicknesses beyond those found on Earth (Fig. 2). Regarding the condition of continental thickness, the crust layer reverberation also causes advances in the P-wave (Yang and Shen 2006). The averages and standard deviations of the time shift differences at periods of 30.0, 21.2, 15.0, 10.6, 7.5, 5.3, and $3.8 \mathrm{~s}$ with respect to a period $2.7 \mathrm{~s}$ are $-0.24 \pm 0.35,-0.30 \pm 0.22$, $-0.31 \pm 0.17,-0.21 \pm 0.11,-0.12 \pm 0.07,-0.06 \pm 0.04$, 
Table 2 Time shift (s) due to reverberation for crustal structures of CRUST2.0 at the points (a-f) shown in Fig. 4 as a function of center period Tc

\begin{tabular}{|c|c|c|c|c|c|c|}
\hline Tc (s) & a & b & c & d & e & $f$ \\
\hline 2.7 & 0.00 & 0.00 & -0.02 & -0.04 & -0.04 & -0.04 \\
\hline 3.8 & 0.00 & 0.00 & -0.06 & -0.06 & -0.08 & -0.08 \\
\hline 5.2 & -0.80 & 0.00 & -0.12 & -0.10 & -0.16 & -0.10 \\
\hline 7.5 & -0.16 & -0.04 & -0.24 & -0.16 & -0.26 & -0.16 \\
\hline 10.6 & 0.18 & -0.10 & -0.38 & -0.26 & -0.46 & -0.22 \\
\hline 15.0 & 0.20 & 0.02 & -0.16 & -0.20 & -0.32 & -0.28 \\
\hline 21.2 & -0.16 & -0.02 & -0.16 & -0.04 & -0.06 & -0.36 \\
\hline 30.0 & -0.56 & -0.42 & -0.62 & -0.22 & -0.48 & -0.06 \\
\hline
\end{tabular}

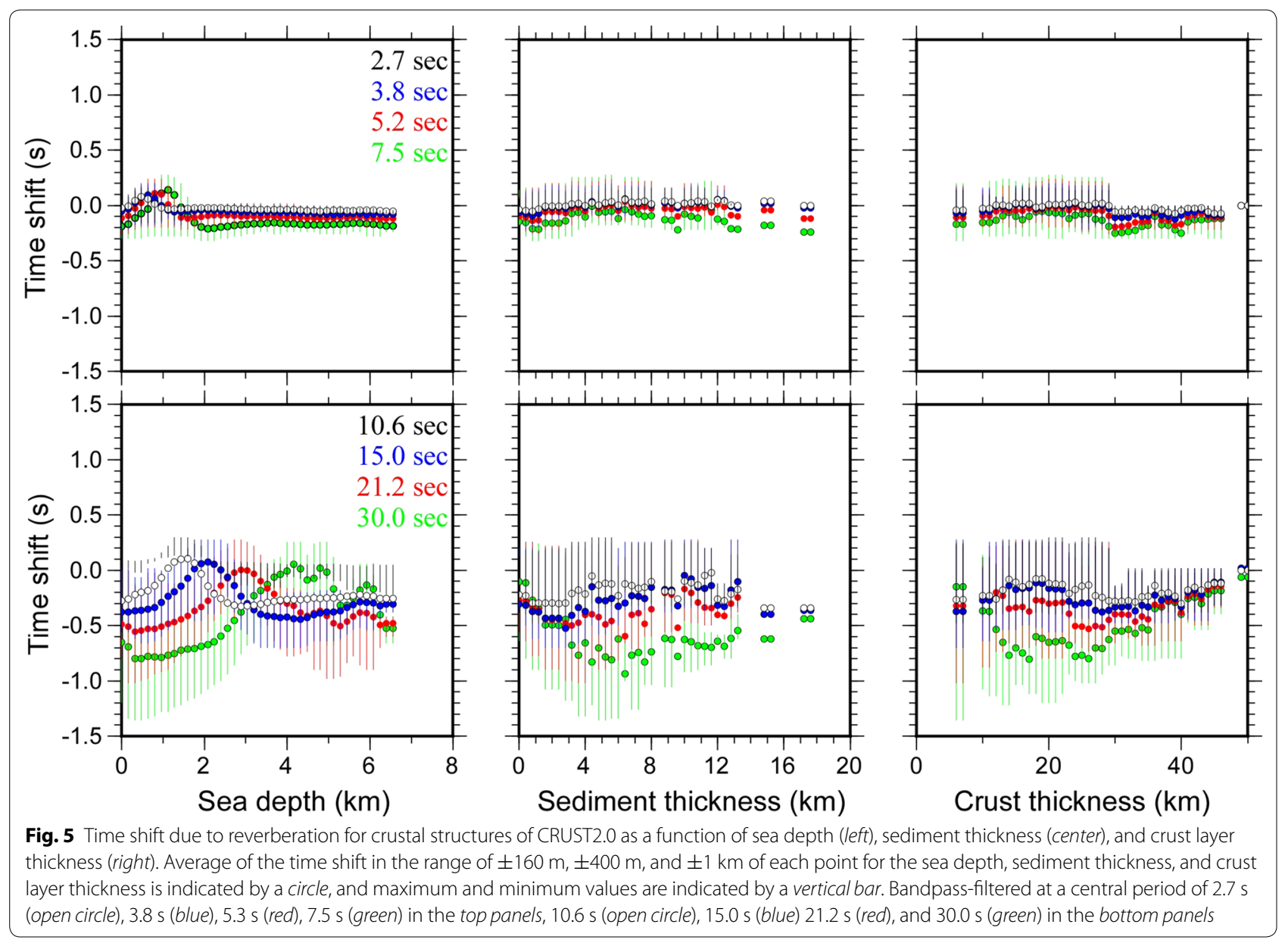

and $-0.02 \pm 0.02 \mathrm{~s}$, respectively, which is comparable to those for continental crust layer.

We compared these values to the effects of mantle heterogeneity by calculating the travel times for an existing three-dimensional velocity model as a function of period based on the finite-frequency theory. We used the P-velocity model obtained by Obayashi et al. (2016) using data from the Tomographic Investigation by seafloor Array Experiment for the Society hot spot (TIARES) BBOBS network (Suetsugu et al. 2012) as the part of global data set including the arrival time data from the International Seismological Centre. The travel times of the TIARES BBOBS network were estimated for all the same events used for the tomography, and root mean 


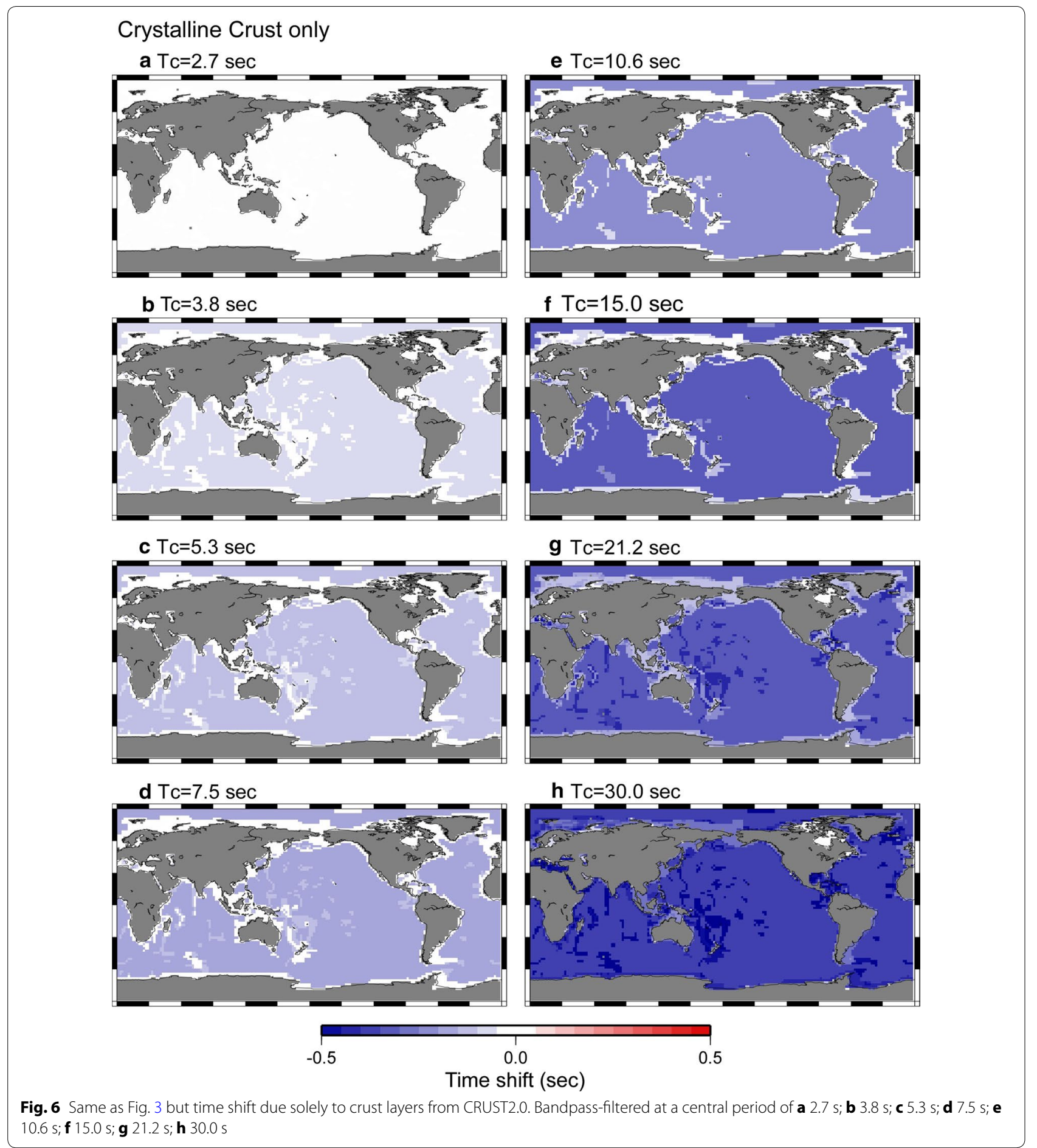

squares of travel time differences at periods of 30.0, 21.2, $15.0,10.6,7.5,5.3$, and $3.8 \mathrm{~s}$ with respect to a period $2.7 \mathrm{~s}$ were $0.28,0.24,0.20,0.14,0.09,0.06$, and $0.03 \mathrm{~s}$, respectively. Amplitudes of these values are comparable to the time shifts caused by the shallow-layer reverberation, indicating that correcting for the shallow-layer reverberation is indispensable for extracting mantle signals.

The synthetic experiment indicated that shallowlayer reverberation could influence the cross-correlation measurements of the relative travel time among a BBOBS array at periods longer than $10 \mathrm{~s}$. We proposed a 


\section{Sediment only}

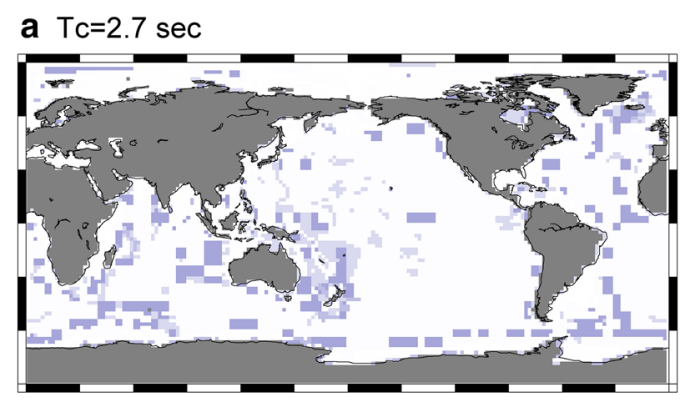

e Tc=10.6 sec
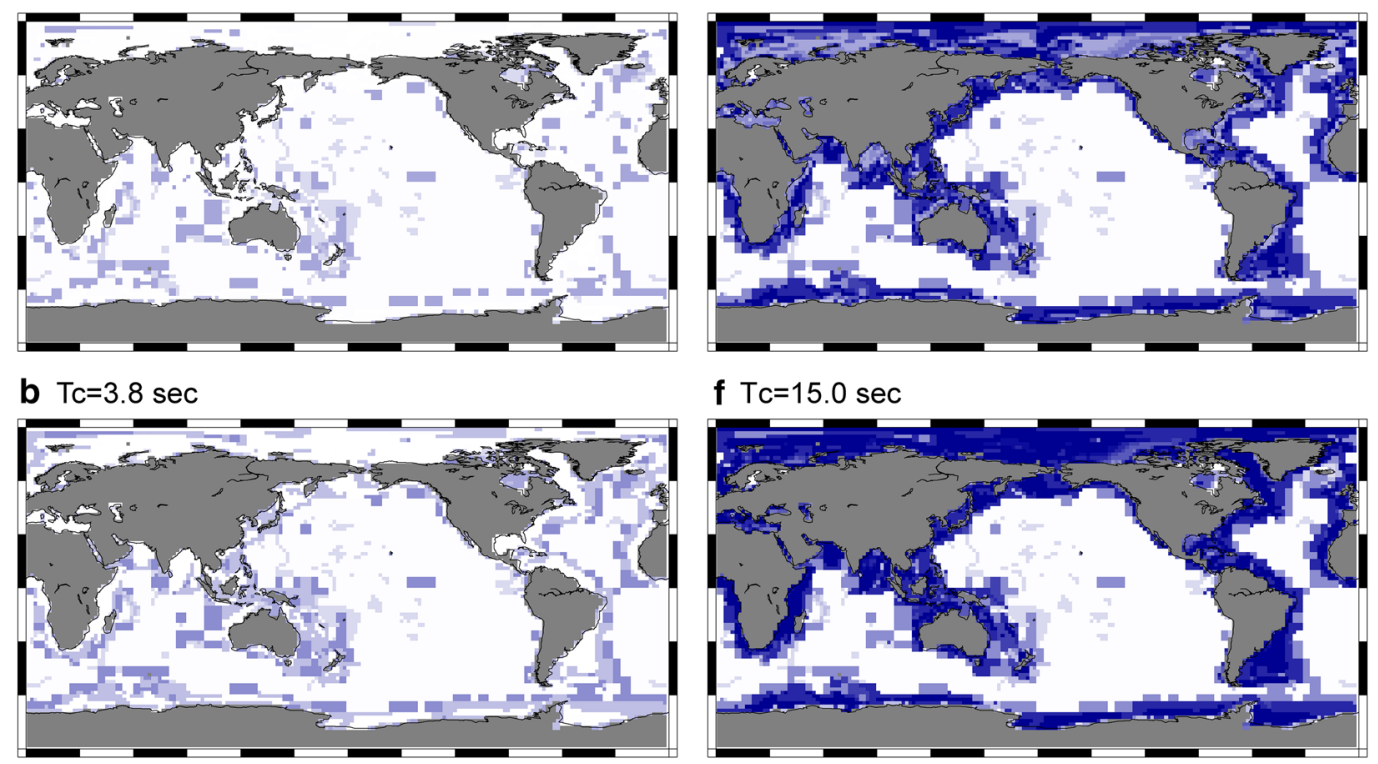

f $\mathrm{Tc}=15.0 \mathrm{sec}$
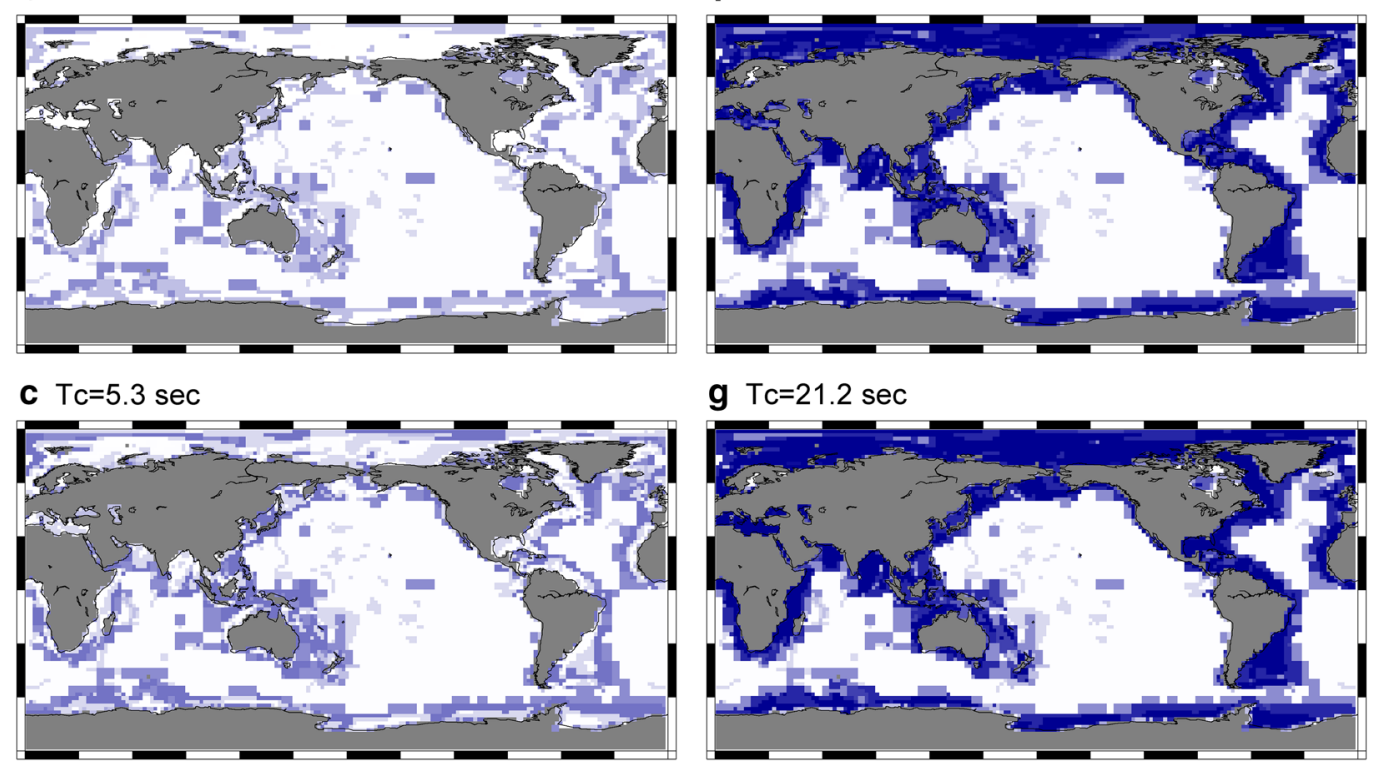

\section{g $\mathrm{Tc}=21.2 \mathrm{sec}$}

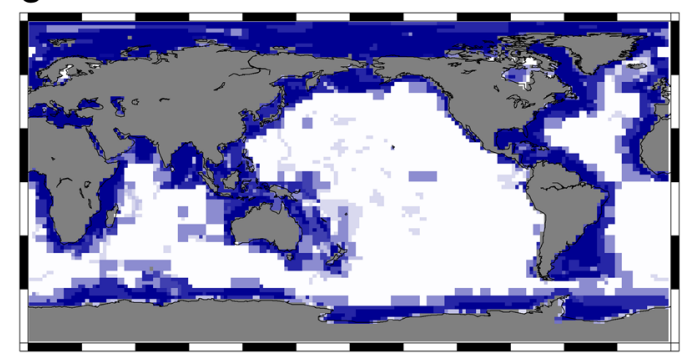

d $\mathrm{Tc}=7.5 \mathrm{sec}$

\section{h $\mathrm{Tc}=30.0 \mathrm{sec}$}
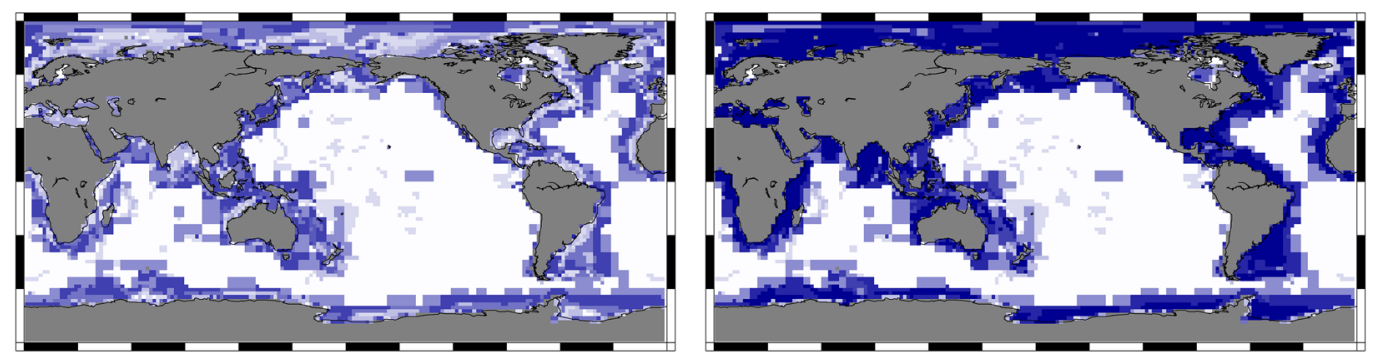

$-0.5$

0.0

0.5

Time shift (sec)

Fig. 7 Same as Fig. 3 but time shift due solely to sediment layers from CRUST2.0. Bandpass-filtered at a central period of a $2.7 \mathrm{~s} ; \mathbf{b} 3.8 \mathrm{~s} ; \mathbf{c} 5.3 \mathrm{~s} ; \mathbf{d} 7.5$ $s ; \mathbf{e} 10.6 \mathrm{~s} ; \mathbf{f} 15.0 \mathrm{~s} ; \mathbf{g} 21.2 \mathrm{~s} ; \mathbf{h} 30.0 \mathrm{~s}$

simple method to correct differential P-wave travel times between two sites for shallow-layer reverberation by cross-convolution of the shallow-layer responses at the two sites. An appropriate shallow-layer model is required for the correction. The crust layer effect is uniform in oceans and is not very sensitive to difference in thickness as shown in Fig. 6; therefore, the global crust models such as CRUST1.0 (Laske et al. 2013) and CRUST2.0 (Bassin et al. 2000) are useful. Global water depths are documented, based on satellite altimetry and echo sounding by ships (e.g., ETOPO2.0). Sediment thickness and velocity may be least documented in the shallow-layer. 


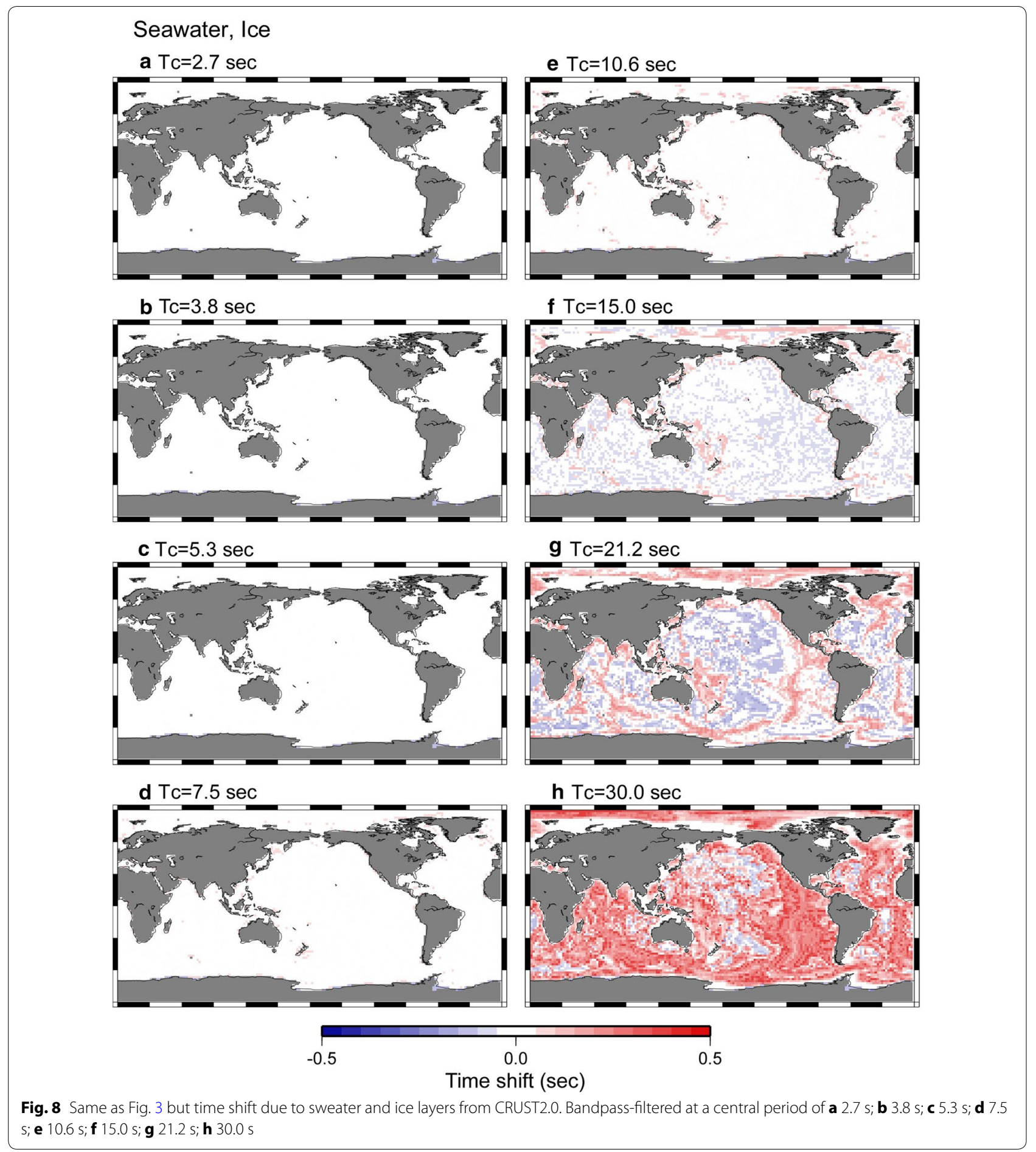

Although the sediment effect is negligible in mid-ocean regions, the effect is significant in regions of sediment thicker than $600 \mathrm{~m}$ such as back-arc basins and seas adjacent to continents. In such regions, it is important to obtain the sediment information (e.g., using an airgun) in addition to data from the global crust models. 
Table 3 Seismic velocity, density and thickness of seawater, sediment and crust layers of AK135 and seafloor models

\begin{tabular}{lllll}
\hline & Seawater & Sediment & Upper crust & Lower crust \\
\hline Vp $(\mathrm{km} / \mathrm{s})$ & 1.500 & 1.600 & 5.525 & 6.900 \\
$V s(\mathrm{~km} / \mathrm{s})$ & 0.000 & 0.879 & 3.250 & 3.875 \\
$\rho\left(\mathrm{g} / \mathrm{cm}^{3}\right)$ & 1.029 & 2.000 & 2.720 & 2.920 \\
AK135 & & & & \\
$\begin{array}{c}\text { Thickness }(\mathrm{km}) \\
\text { Seafloor model }\end{array}$ & 0.0 & 0.0 & 20.0 & 15.0 \\
$\begin{array}{c}\text { Thickness }(\mathrm{km}) \\
\text { The }\end{array}$ & 4.0 & 0.5 & 1.5 & 5.0 \\
\hline
\end{tabular}
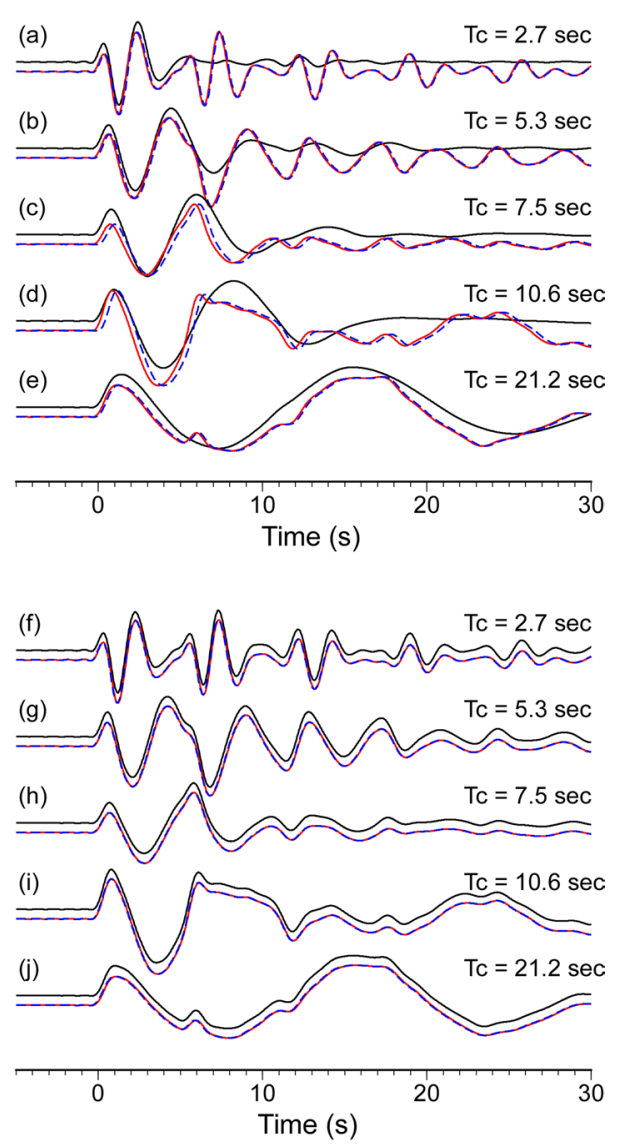

Fig. 9 Top synthetic seismograms for the two shallow-layer models shown in Table 3. Bottom synthetic seismograms for the two shallowlayer models after cross-convolving the responses for each other's shallow-layer structure. Waveforms for the AK135 model are shown in black and waveforms for the seafloor model are shown in red via time shifting by the ray theoretical travel time difference between the two shallow-layer models and by broken blue lines at times of maximum correlation with synthetics for the AK135 model. Bandpass filter is applied at a central period of $(a, f) 2.7,(b, g) 5.3,(c, h) 7.5(d, i), 10.6$ and $(e, j) 21.2 \mathrm{~s}$

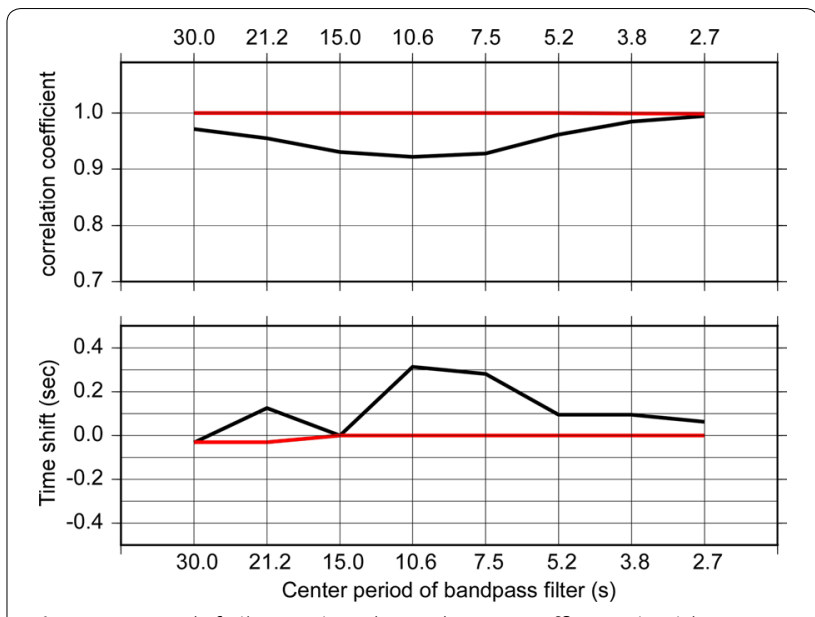

Fig. 10 Time shift (bottom) and correlation coefficient (top) between synthetic seismograms for the two shallow-layer models as a function of central period of bandpass filter. (Black) Before the correction; (red) after the correction

\section{Additional file}

Additional file 1: Figure A. Bathymetry, sediment thickness, and crust thickness from CRUST2.0.

\section{Authors' contributions}

MO designed this study, carried out the synthetic analysis, and prepared the manuscript. All authors discussed and devised the proposed method. All authors read and approved the final manuscript.

\section{Author details}

${ }^{1}$ Department of Deep Earth Structure and Dynamics Research, Japan Agency for Marine-Earth Science and Technology, 2-15 Natsushima-cho, Yokosuka 237-0061, Japan. ${ }^{2}$ Research and Development Center for Earthquake and Tsunami, Japan Agency for Marine-Earth Science and Technology, 3173-25, Showamachi, Yokohama 236-0001, Japan.

\section{Acknowledgements}

We would like to thank the reviewers for their comments that helped us to improve the manuscript. This work was supported by Grant-in-Aid for Scientific Research (KAKENNHI, JP25287116, JP15H03720) from the Japan Society for the Promotion of Science. The GMT software package (Wessel and Smith 1991) was used in this study.

\section{Competing interests}

The authors declare that they have no competing interests.

Received: 29 December 2016 Accepted: 9 March 2017

Published online: 21 March 2017

\section{References}

Bassin C, Laske G, Masters G (2000) The current limits of resolution for surface wave tomography in North America. EOS Trans AGU 81:F897 
Blackman DK, Orcutt JA, Forsyth D (1995) Recording teleseismic earthquakes using ocean-bottom seismographs at mid-ocean ridges. Bull Seismol Soc Am 85:1648-1664

Haskell NA (1962) Crustal reflection of plane P and SV waves. J Geophys Res 67:4751-4767

Kennett BLN, Engdahl ER, Buland R (1995) Constraints on seismic velocities in the Earth from travel times. Geophys J Int 122:108-124

Kolstrup ML, Maupin V (2015) Measuring and crust-correcting finite-frequency travel time residuals_-application to southwestern Scandinavia. Solid Earth 6:1117-1130

Laske G, Masters G, Ma Z, Pasyanos M (2013) Update on CRUST1.0_a 1-degree global model of Earth's Crust. Geophys Res Abstracts 15, Abstract EGU2013-2658

Obayashi M, Suetsugu D, Fukao Y (2004) PP-P differential traveltime measurement with crustal correction. Geophys J Int 157:1152-1162

Obayashi M, Yoshimitsu J, Nolet G, Fukao Y, Shiobara H, Sugioka H, Miyamachi H, Gao Y (2013) Finite frequency whole mantle P wave tomography: Improvement of subducted slab images. Geophys Res Lett 40:5652-5657

Obayashi M, Yoshimitsu J, Sugioka H, Ito A, Isse T, Shiobara H, Reymond D, Suetsugu D (2016) Mantle plumes beneath the South Pacific superswel revealed by finite frequency $P$ tomography using regional seafloor and island data. Geophys Res Lett 43:11628-11634
Suetsugu D, Shiobara H (2014) Broadband ocean bottom seismology. Ann Rev Earth Planet Sci 42:27-43

Suetsugu D, Shiobara H, Sugioka H, Ito A, Isse T, Kasaya T, Tada N, Baba K, Abe N, Hamano Y, Tarits P, Barriot JP, Reymond D (2012) TIARES Projecttomographic investigation by seafloor array experiment for the Society hotspot. Earth Planets Space 64:i-iv

Takeuchi N, Geller RJ, Cummins PR (1996) Highly accurate P-SV complete synthetic seismograms using modified DSM operators. Geophys Res Lett 23:1175-1178

Wessel P, Smith WHF (1991) Free software helps map and display data. EOS Trans AGU 72(441):445-446

Wolfe CJ, Solomon SC, Laske G, Detrick RS, Orcutt JA, Bercovici D, Hauri EH (2009) Mantle shear-wave velocity structure beneath the Hawaiian hot spot. Nature 326:1388-1390

Wolfe CJ, Solomon SC, Laske G, Collins JA, Detrick RS, Orcutt JA, Bercovici D, Hauri EH (2011) Mantle P-wave velocity structure beneath the Hawaiian hotspot. Earth Planet Sci Lett 303:267-280

Yang T, Shen Y (2006) Frequency-dependent crustal correction for finitefrequency seismic tomography. Bull Seismol Soc Am 96:2441-2448

\section{Submit your manuscript to a SpringerOpen ${ }^{\odot}$ journal and benefit from:}

- Convenient online submission

- Rigorous peer review

- Immediate publication on acceptance

- Open access: articles freely available online

- High visibility within the field

- Retaining the copyright to your article 